\title{
Visual versus video methods for estimating reef fish biomass
}

\author{
SK Wilson, NAJ Graham, TH Holmes, MA Mac Neil, NM Ryan
}

\begin{abstract}
Introduction
\end{abstract}

Estimates of coral reef fish body size are commonly collected in situ using underwater visual census (UVC). In combination with abundance data, species specific body size can give a fisheries independent estimate of fish biomass (Graham and McClanahan 2013). Such community level measures of biomass are useful indicators of fishing pressure (Nash and Graham 2016) and can provide assessments of fish community condition relative to natural and anthropogenic drivers of change (MacNeil et al. 2015; Cinner et al. 2016). Spatial and temporal variation in fish biomass can also be used to identify ecological thresholds for ecosystem based management of fisheries (McClanahan et al. 2011), whilst comparing biomass at different trophic levels can elucidate understanding of trophodynamics (Trebilco et al. 2013; Graham et al. 2017).

Underwater video is an increasingly popular method for monitoring fish communities in temperate and tropical locations around the globe (Mallet and Pelletier 2014). A major advantage of video techniques is that images can be repeatedly scrutinised to identify taxa, verify findings or garner new information (Wilson et al. 2009; Bennett et al. 2016). The use of stereo cameras or laser also facilitate accurate length and / or depth measures of fish (Harvey et al. 2002), which may be combined with species specific length weight relationships and abundance data to calculate community biomass. Comparisons between UVC and video techniques have found the two methods produce comparable estimates of numeric abundance for some taxa (Bortone et al. 1991; Tessier et al. 2005). However, abundance of cryptic species may be underestimated, particularly in structurally complex and highly diverse systems like coral reefs (Pelletier et al. 2011; Holmes et al. 2013). Furthermore, videos are typically unable to estimate the length of all fish observed during filming (Watson et al. 2010; Goetze et al. 2017), as the entire body may not be captured, be partially obscured by other objects in the video, or recorded at an angle that prevents accurate measurement (Harvey et al. 2010; Harasti and Malcolm 2013). The size of observed but unmeasured fish may be estimated from similar taxa whose size was accurately measured (Lindfield et al. 2014; AndradiBrown et al. 2016), though the compatibility of fish community biomass estimates from video and UVC remains equivocal.

We compared fish community biomass estimates from UVC and stereo-DOV recordeding fish, species size and abundance using both methods at the same coral reef sites in the Ningaloo Marine Park, Western Australia. We also examined size distributions of fish data captured from the two methods and determine which families contribute most to any differences in the methods.

Methods 
Fish surveys were conducted in April/May 2016 at eight sites in the Ningaloo Marine Park, located on the western coast of Australia. Four of the sites were within no-take sanctuary zones and four were in adjacent areas where fishing was permitted. All sites were on shallow $(2-4 \mathrm{~m})$ coral reefs within a lagoon, which is protected from oceanic swells by a fringing reef. At each site fish size and abundance was estimated along six 50m long transects using both UVC and stereo diver operated video (DOV). Three of the $50 \mathrm{~m}$ transects were initially surveyed using UVC for all large ( $T L>8 \mathrm{~cm}$ ), non-cryptic, diurnal fish, other than pomacentrids, within a $5 \mathrm{~m}$ wide transect. A second pass of the transect recorded all pomacentrids (including $<8 \mathrm{~cm} \mathrm{TL}$ ) within a $2 \mathrm{~m}$ wide transect, as smaller bodied fish are typically recorded over narrower transects to increase precision of estimates (Sale and Sharp 1983; Cheal and Thompson 1997). The other three transects were initially surveyed using stereoDOV. The DOV transects were swum at a consistent swimming pace of around $0.5 \mathrm{~m} / \mathrm{s}$ and at a height of no more than $1 \mathrm{~m}$ above the substrate. The stereo-DOV cameras faced directly ahead and avoided sudden sideway movements as per Holmes et al. (2013). Once DOV transects were completed the same transects were surveyed using UVC, while the 3 transects surveyed first using UVC were surveyed using DOV.

The DOV unit consisted of two high definition Sony HG21 digital video cameras inside underwater housings mounted $0.7 \mathrm{~m}$ apart on a neutrally buoyant metal base bar and angled inward at $8^{\circ}$ (Harvey and Shortis 1996). A bar with a synchronising diode was attached to the centre of the base bar so that the diode is in the field of view of both cameras allowing frames from the two cameras to be synchronised.

Video footage collected by DOV was analysed using the program EventMeasure Stereo v3.54 (SeaGIS Pty Ltd). The stereo component of the program was used to simultaneously record species identification (to the highest possible taxonomic level) and total length (TL mm; snout to the furthest tip of the caudal fin) measurements. Where an accurate length measurement could not be obtained, a three-dimensional point on the location of the fish recorded its identy. As with UVC, fish from the family Pomacentridae were recorded on a transect of $2 \mathrm{~m}$ width and non-pomacentrids with a TL greater than $8 \mathrm{~cm}$ were recorded on a $5 \mathrm{~m}$ transect width. All records were limited to within $7 \mathrm{~m}$ of the cameras to maintain high levels of measurement accuracy and precision (Harvey et al. 2002).

As reef structure may obscure fish and contribute to differences in biomass estimates between the methods, structural complexity of each transect was evaluated. We used a visual 0-5 complexity measure, whereby transects with low structural complexity and no vertical relief scored 0 , whilst at the other extreme those with numerous caves, overhangs and exception complexity scored 5 (Polunin and Roberts 1993). The method has proved valuable in capturing variation in reef fish abundance, biomass and diversity in other studies (Wilson et al. 2007; Darling et al. 2017).

\section{Statistical analyses}

Length estimates from for each fish were converted to weights using species specific length-weight relationships (Froese and Pauly 2017) and summed to provide a biomass estimate for each transect. When species specific relationships were not available, parameters from a closely related fish were used to calculate fish weight. Biomass estimates based on DOV data either excluded fish whose length could not be measured, or assumed the length of these fish was the median value of DOV measured fish from the same taxa (DOV+Med). Analyses therefore included both methods, termed 
'DOV' when including only fish that could be measured, and 'DOV+Med' when including all fish and the median size rule.

Methodological differences in biomass estimates of fish were assessed using repeated measure Permutational Multivariate Analysis of Variance (PERMANOVA) in PRIMER-E version 7 software (Anderson et al. 2008). Method (UVC, DOV or DOV+Med) was considered a repeated measure in analyses as data were collected along the same transect. Management status (fished or no-take zone) was entered into the analysis as a fixed factor, and site a random factor nested in management status. Structural complexity was included as a covariate. PERMANOVA were carried out on biomass data collated to the family level. All biomass data (pomacentrid and nonpomacentrid) were converted to kg.Ha prior to analyses and a resemblance matrix constructed using a Bray-Curtis similarity measure. Significant differences were further investigated with pairwise PERMANOVA and visualised using canonical analysis of principal components (CAP) constrained by method.

Results

A total of 9728 individuals representing 119 species from 24 families were recorded by UVC whilst 12370 individuals from 100 species and 20 families were recorded by DOV. More than half of the fish recorded by UVC (5322/9728) and DOV (8067/12370) were pomacentrids (Table 1), both methods identifying the same 18 species from this family. The DOV recorded $68 \%$ more signaids, $50 \%$ more pomacentrids, and $28 \%$ more acanthurids than UVC, whilst UVC reordered three times as many serranids, twice as many mullids and $43 \%$ more chaetodontids. Length measures were acquired for all fish recorded by UVC, however body lengths were obtained for only 2161/8067 (27\%) of pomacentrids and 2954/4303 (69\%) of non-pomacentrids when using DOV.

Total biomass of fish (pomacentrid + non-pomacentrids) based on UVC data was $~ 800 \mathrm{~kg}$. Ha, which was $\sim 50 \%$ greater than biomass calculated from DOV data excluding the unmeasured fish (Figure 1). When fish that could not be measured by the DOV were assumed to be of median size to those that were measured by DOV, biomass estimates from UVC and DOV+Med were statistically similar. Total biomass also differed among sites, although management (fished or no take sanctuary zones) and habitat complexity did not significantly effect total fish biomass (Table 2).

Differences between UVC and DOV estimates excluding unmeasured fish were primarily due to greater biomass of scarids and nemipterids on UVC (Figure 2a), though these surveys are also characterised by high biomass of labrids and cheatodontids (Figure $2 \mathrm{c}$ ). Including biomass estimates of unmeasured fish generally made UVC and DOV+Med measures at the family level more comparable, however DOV+Med estimates for acanthurids, pomacentrids and siganids were much higher than those from UVC (Figure 2a).

High DOV+Med biomass estimates for acanthurids, pomacentrids and siganids relate to the large number of fish and higher median sizes for these families when using DOV (Table 1). Differences in the size distributions of fish obtained from the two methods are also noticeable (Figure 3). The UVC method typically recorded more fish in the smaller size classes, the number of pomacentrids $<3 \mathrm{~cm}$ being an order of magnitude higher when using UVC compared to DOV (Figure 3a, b). However, the biomass of these lower size classes did not contribute greatly to the overall biomass of fish or to differences between methods (Figure 3c, d). Conversely, relatively small differences in the numeric 
estimates of larger bodied fish transferred into large differences in biomass and high levels of variability between methods.

Abundance of fish often targeted by fishers was low irrespective of the method used, the combined biomass of serranids, lethrinids and lutjanids accounting for $<5 \%$ of the total community biomass (Figure 2b). Although abundance estimates from both methods were low for these fish, UVC recorded three times more serranids than DOV and only 3/7 serranids observed on DOV were measured (Table 1). Abundance estimates of lutjanids and lethrinids were similar among the two methods, although only 6/41 lutjanids were measured as these fish were in a large school and some fish were partially obscured by other fish or the coral they were sheltering under.

Table 1. Abundance and size of fish from prominent families recorded using either diver operated video (DOV) or underwater visual census (UVC) across eight sites, each with six transects. Transects for surveying pomacentrids were $2 \times 50 \mathrm{~m}$, whilst those for all other fish were $5 \times 50 \mathrm{~m}$. Figures in parentheses are standard deviations.

\begin{tabular}{lllllllll} 
& \multicolumn{3}{l}{$\begin{array}{l}\text { Number } \\
\text { observed }\end{array}$} & \multicolumn{2}{l}{$\begin{array}{l}\text { Number } \\
\text { measured }\end{array}$} & \multicolumn{2}{l}{$\begin{array}{l}\text { length }(\mathrm{cm}) \\
\text { lenge }\end{array}$} & \multicolumn{2}{l}{$\begin{array}{l}\text { Median length } \\
\text { (cm) }\end{array}$} \\
\hline Family & DOV & DOV & UVC & DOV & UVC & DOV & UVC \\
\hline Acanthuridae & 855 & 668 & 516 & 668 & $18(4)$ & $15(4)$ & 17 & 14 \\
Chaetodontidae & 106 & 152 & 67 & 152 & $12(2)$ & $11(1)$ & 11 & 12 \\
Labridae & 775 & 917 & 660 & 917 & $13(6)$ & $14(5)$ & 12 & 12 \\
Lethrinidae & 27 & 28 & 18 & 28 & $28(11)$ & $30(6)$ & 25 & 31 \\
Lutjanidae & 41 & 48 & 6 & 48 & $27(5)$ & $24(2)$ & 26 & 23 \\
Mullidae & 26 & 56 & 21 & 56 & $19(5)$ & $20(9)$ & 19 & 17 \\
Nemipteridae & 115 & 111 & 80 & 111 & $18(3)$ & $20(4)$ & 18 & 20 \\
Pomacanthidae & 25 & 25 & 13 & 25 & $15(5)$ & $14(5)$ & 12 & 11 \\
Pomacentridae & 8067 & 5322 & 2161 & 5322 & $6(3)$ & $4(3)$ & 6 & 4 \\
Scaridae & 1927 & 2021 & 1393 & 2021 & $18(7)$ & $18(7)$ & 19 & 15 \\
Serranidae & 7 & 23 & 3 & 23 & $26(9)$ & $26(8)$ & 28 & 24 \\
Siganidae & 369 & 219 & 156 & 219 & $22(4)$ & $21(3)$ & 22 & 20 \\
\hline
\end{tabular}


Table 2. Statistical results for biomass data. Analysis variables were: habitat complexity (HC), management status (MS), method (Me) and site (S).

\begin{tabular}{rrrr}
\cline { 3 - 4 } Source & df & $\mathrm{F}$ & $p$-value \\
\hline$(\mathrm{HC})$ & 1 & 2.644 & 0.140 \\
$(\mathrm{MS})$ & 1 & 0.419 & 0.539 \\
$(\mathrm{Me})$ & 2 & 5.594 & $\mathbf{0 . 0 0 4}$ \\
$(\mathrm{S})$ & 6 & 9.448 & $\mathbf{0 . 0 0 0 1}$ \\
$(\mathrm{HC} \times \mathrm{Me})$ & 2 & 0.177 & 0.896 \\
$(\mathrm{MS} \times \mathrm{Me})$ & 2 & 0.075 & 0.976 \\
Res & 129 & & \\
Total & 143 & & \\
\hline
\end{tabular}

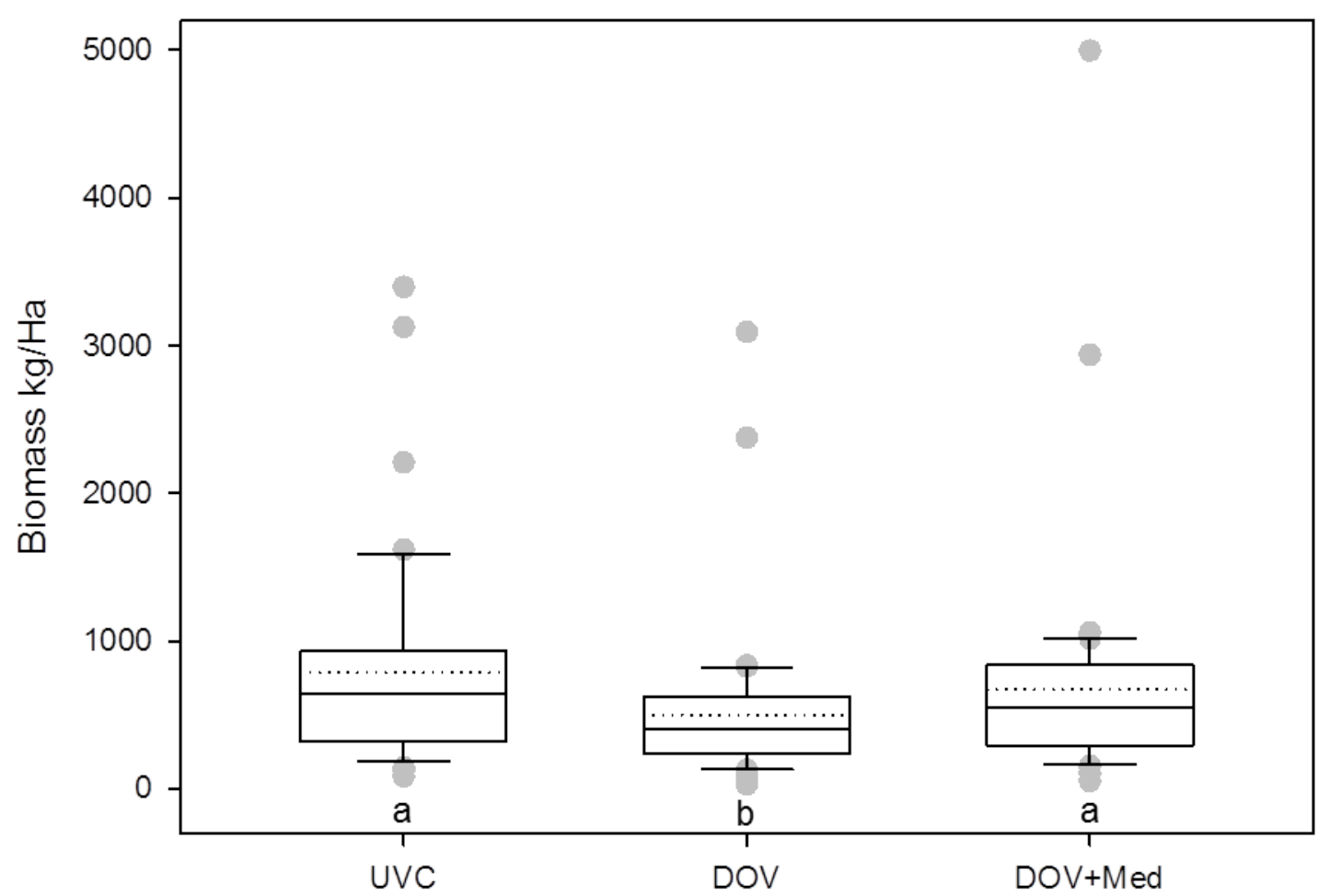

Figure 1. Plot representing total community biomass estimates from UVC and DOVs. The DOV+Med estimate incorporated information on fish whose length could not be measured with DOV and is based on the median values of all fish from that taxa observed and measured by DOV. Estimates are site averages from all transects $(n=48)$. Letters denote similar values based on pairwise PERMANOVA. Box and whiskers illustrate; medians (solid horizontal line), means (dotted horizontal line), $50^{\text {th }}$ percentile (box outline), $90^{\text {th }}$ percentile (whiskers) and outliers (grey circles). 


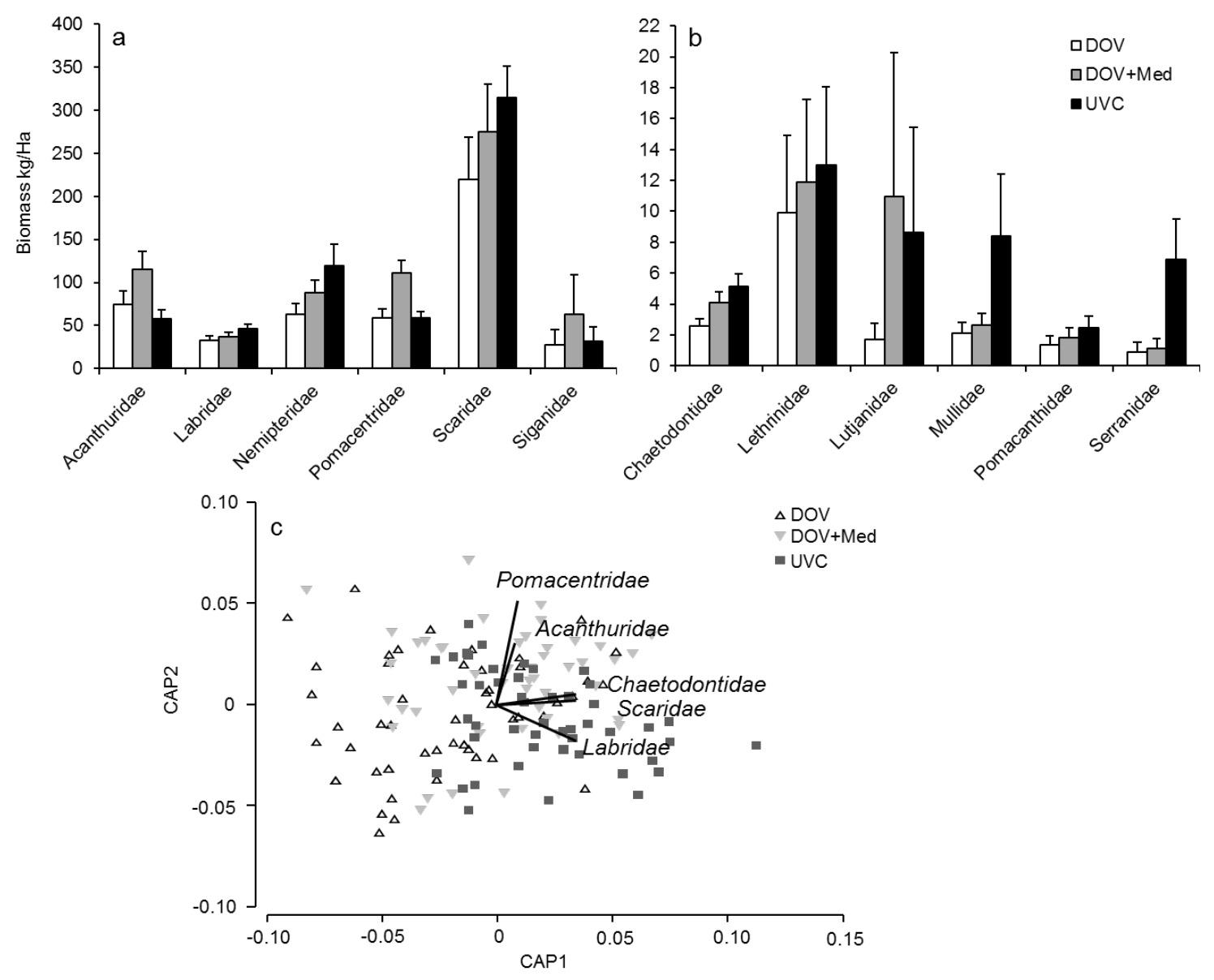

Figure 2. Biomass of fish families at Ningaloo that make a) large $(>20 \mathrm{~kg} / \mathrm{Ha})$ or b) smaller contributions to community biomass estimates. Mean with standard error biomass estimates are calculated form underwater visual census (UVC), diver operated video (DOV), or DOV data plus median values for unmeasured fish (DOV+Med) carried out at eight sites. Community level differences among the methods are displayed using canonical analysis of principal coordinates (CAP) with family correlations $(r>0.35)$ shown as an overlay. 


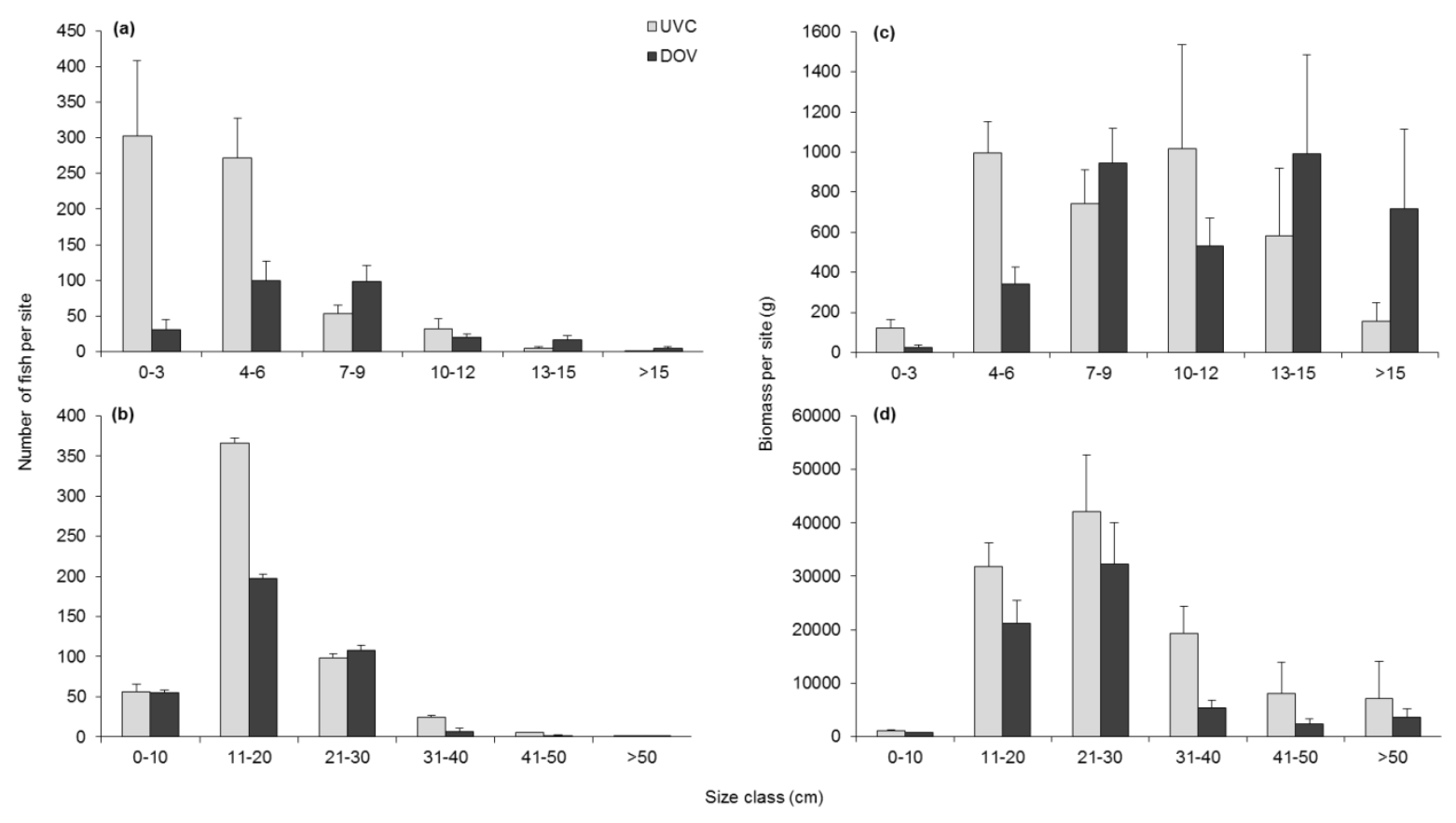

Figure 3. Abundance and biomass distributions of for pomacentrids $(a, c)$ and non-pomacentrids $>8 \mathrm{~cm}$ TL $(b, d)$. Distributions presented as site averages with SE $(n=8)$.

\section{Discussion}

Biomass estimates of coral reef fish at Ningaloo are significantly higher when based on information from UVC rather than DOV. Disparity between the two methods is partially due to DOV being unable to measure the length of some of the fish observed on video. When the size of these unmeasured fish was assumed to be the median length of similar taxa, whose length was measured by DOV, total biomass estimates from the two methods were statistically similar. These results suggest total biomass calculated from DOV and UVC is compatible. However, even after corrections to DOV data there are differences in biomass among size categories and fish families that suggest there are important differences between biomass estimates from UVC and DOV.

The UVC generally recorded more small bodied fish than DOV, even though divers often overestimate the size of small fish (Edgar et al. 2004). This discrepancy was most noticeable among the pomacentrids, where ten times as many fish $<3 \mathrm{~cm}$ were counted on UVC than DOV. Conversely, DOV recorded almost twice as many pomacentrids than UVC, though most of these were not measured. This result infers that many of the pomacentrids observed, but not measured, on the video were small juveniles and that the median size of fish measured by DOV is excessive. Consequently, DOV+Med biomass estimates of pomacentrids are likely to be unreasonably high.

Large differences between UVC and DOV estimates of small, highly abundant fish such as pomacentrids have previously been documented, though in some cases DOV estimates are higher (Bortone et al. 1991; Holmes et al. 2013) and in others UVC is higher (Pelletier et al. 2011; Goetze et al. 2015), reflecting the difficulty in assessing the abundance of small, highly abundant, fish with non-destructive techniques (Ackerman and Bellwood 2000). Species diversity of coral reef fish assemblages is however greatest in size classes $<10 \mathrm{~cm}$ (Munday and Jones 1998) and small fish play 
important roles in marine trophodynamics (Depczynski et al. 2007). Moreover, the abundance of small bodied recruits can be closely linked to future adult fish abundance and is an essential component of population modelling (Tolimieri 2015). The ability to detect and measure small fish by video may improve by changing the angle and distance at which cameras are set apart on the DOV frame (Turner et al. 2015; Depczynski et al. 2017). However, the large discrepancies in size distributions from UVC and DOV data observed here infer it is inappropriate to combine abundance data of small bodied fish from the two methods.

We also found that small differences in size estimates of larger bodied fish can magnify differences in weight and total community biomass estimates. Larger bodied fish often contribute more to the total biomass of the assemblage than highly abundant small bodied species (Ackerman et al. 2004), emphasising the importance of accurately estimating the size of large bodied individuals. Stereo video typically provides more accurate measures of fish than UVC (Harvey et al. 2002; Bower et al. 2011), suggesting this method provides a more accurate assessment of individual fish weight. But total community biomass estimates are dependent on large fish being both detected and measured and for some taxa UVC detected and measured more fish than DOV.

Differences in biomass estimates between the two methods are also apparent among some key taxa. Serranids are targeted by fishers on may corals reefs, including Ningaloo (Sadovy de Mitcheson et al. 2013; Ryan et al. 2015), and their abundance is often monitored to assess the effects of fishing (Russ et al. 2008). We found that biomass estimates of serranids from DOV were low compared to UVC, primarily due to fewer fish being detected on video. Most serranids are closely associated with the benthos, where they hide in small crevices and caves (Sluka 2000). This cryptic behaviour means abundance of these, and other benthic species, is generally low on DOVS, especially when the technique precludes extensive searching of the reef (Pelletier et al. 2011; Holmes et al. 2013). Encouragingly abundance of lethrinids and lutjanids, which are also often targeted by fishers, were similar, though size estimates were obtained for very few of the schooling lutjanids in DOVS. Inability to measure all fish in a school may not be a problem if fish are of a similar size and at least some can be measured. Moreover, abundance of schooling fish is often estimated or rounded off when using UVC and size estimates are grouped. Hence idiosyncrasies associated with each method contribute to inaccuracy and methodological differences of biomass estimates of schooling fish.

Large bodied fish are also often targeted by fishers, but are generally wary and stay further from divers than smaller counterparts (Januchowski-Hartley et al. 2015; Goetze et al. 2017). This may inhibit detection by DOV, especially if the cameras field of view is restricted. At Ningaloo, UVC record three times more fish $>30 \mathrm{~cm}$ than DOV, somewhat supporting this notion. Conversely, abundance of some fish may be overestimated by UVC when fish are inadvertently counted from outside the bounds of the transect. This is less of a concern with DOV as the position of fish can be accurately mapped relative to transect boundaries (Harvey et al. 2004)

On a global scale fishing pressure at Ningaloo is low and targets predatory species like lethrinids and serranids (Halpern et al. 2008; Ryan et al. 2015), suggesting biomass levels at Ningaloo should be sustainable (Graham et al. 2017). Total fish biomass estimates at Ningaloo based on UVC data are similar to those from some no-take marine reserves with strong compliance in the Indian Ocean (McClanahan et al. 2009), but are less than the $1000 \mathrm{~kg}$.Ha expected in the total absence of fishing (MacNeil et al. 2015). Nonetheless, we found little difference in total biomass in fished and unfished 
areas, which is consistent with recent findings that habitat quality is a better predictor of fish biomass than fishing on patch reefs in the Ningaloo lagoon (Wilson et al. 2012). Illegal fishing in notake areas may have influenced these results (Smallwood and Beckley 2012), though the relatively high values obtained at Ningaloo infer fishing has had a comparatively small effect on total biomass compared to other parts of the world.

Our results indicate that total biomass estimates from DOV and UVC are similar when DOV estimates are corrected for unmeasured fish. Combining data from the two methods may increase the spatial and temporal scope of monitoring programs, potentially improving understanding of environmental and anthropogenic drivers of changes to fish communities. However, the methods are less likely to be compatible when comparing data from small bodied and cryptic taxa, or where the size distributions of fish acquired from the two methods differ markedly.

References

Ackerman JL, Bellwood DR (2000) Reef fish assemblages: a re-evaluation using enclosed rotenone stations. Mar Ecol-Prog Ser 206:227-237.

Ackerman JL, Bellwood DR, Brown JH (2004) The contribution of small individuals to density-body size relationships: examination of energetic equivalence in reef fishes. Oecologia 139:568-571. doi: 10.1007/s00442-004-1536-0

Anderson M, Gorley RN, Clarke RK (2008) Permanova+ for Primer: Guide to Software and Statisticl Methods.

Andradi-Brown DA, Gress E, Wright G, et al (2016) Reef Fish Community Biomass and Trophic Structure Changes across Shallow to Upper-Mesophotic Reefs in the Mesoamerican Barrier Reef, Caribbean. PLOS ONE 11:e0156641. doi: 10.1371/journal.pone.0156641

Bennett K, Wilson S k., Shedrawi G, et al (2016) Can diver operated stereo-video surveys for fish be used to collect meaningful data on benthic coral reef communities? Limnol Oceanogr Methods 14:874-885. doi: 10.1002/lom3.10141

Bortone SA, Martin T, Bundrick CM (1991) Visual census of reef fish assemblages: A comparison of slate, audio, and video recording devices. Northeast Gulf Sci 12:17-23.

Bower MR, Gaines DB, Wilson KP, et al (2011) Accuracy and Precision of Visual Estimates and Photogrammetric Measurements of the Length of a Small-bodied Fish. North Am J Fish Manag 31:138-143. doi: 10.1080/02755947.2011.562737

Cheal AJ, Thompson AA (1997) Comparing visual counts of coral reef fish: implications of transect width and species selection. Mar Ecol Prog Ser 158:241-248.

Cinner JE, Huchery C, MacNeil MA, et al (2016) Bright spots among the world's coral reefs. Nature 535:416-419. doi: 10.1038/nature18607

Depczynski M, Fulton CJ, Marnane MJ, Bellwood DR (2007) Life history patterns shape energy allocation among fishes on coral reefs. Oecologia 153:111-120. doi: 10.1007/s00442-007-0714-2 
Depczynski M, Gilmour JP, Vanderklift M, et al (2017) Key Ecological processes in Kimberley benthic comunities: recruitment and Herbivory. Final report of Project 1.1.2 of the Kimberley Marine Research Program prepared for the Wetsern Australian Marine Science Institution. WAMSI, Perth, Western Australia.

Edgar GJ, Barrett NS, Morton AJ (2004) Biases associated with the use of underwater visual census techniques to quantify the density and size-structure of fish populations. J Exp Mar Biol Ecol 308:269-290. doi: 10.1016/j.jembe.2004.03.004

Goetze J, januchowski-Hartley F, Claudet J, et al (2017) Fish wariness is a more sensitive indicator to chnages in fishing pressure than abundance, length or biomass.

Goetze JS, Jupiter SD, Langlois TJ, et al (2015) Diver operated video most accurately detects the impacts of fishing within periodically harvested closures. J Exp Mar Biol Ecol 462:74-82.

Graham N, Dulvy N, Jennings S, Polunin N (2005) Size-spectra as indicators of the effects of fishing on coral reef fish assemblages. Coral Reefs 24:118-124. doi: 10.1007/s00338004-0466-y

Graham NAJ, McClanahan TR (2013) The Last Call for Marine Wilderness? BioScience 63:397-402. doi: 10.1525/bio.2013.63.5.13

Graham NAJ, McClanahan TR, MacNeil MA, et al (2017) Human Disruption of Coral Reef Trophic Structure. Curr Biol 27:231-236. doi: 10.1016/j.cub.2016.10.062

Halpern BS, Walbridge S, Selkoe KA, et al (2008) A Global Map of Human Impact on Marine Ecosystems. Science 319:948-952. doi: 10.1126/science.1149345

Harasti D, Malcolm H (2013) Distribution, relative abundance and size composition of the threatened serranid Epinephelus daemelii in New South Wales, Australia. J Fish Biol 83:378-395.

Harvey E, Fletcher D, Shortis M (2002) Estimation of reef fish length by divers and by stereo-video: a first comparison of the accuracy and precision in the field on living fish under operational conditions. Fish Res 57:255-265.

Harvey E, Fletcher D, Shortis M, Kendrick G (2004) A comparison of underwater visual distance estimates made by scuba divers and a stereo-video system: implications for underwater visual census of reef fish abundance. Mar Freshw Res 55:573-580. doi: doi:10.1071/MF03130

Harvey ES, Goetze J, McLaren B, et al (2010) Influence of range, angle of view, image resolution and image compression on underwater stereo-video measurements: highdefinition and broadcast-resolution video cameras compared. Mar Technol Soc J 44:75-85.

Harvey ES, Shortis M (1996) A system for stereo-video measurment of sub-tidal organism. Mar Technol Soc 29:10-22.

Holmes TH, Wilson SK, Travers MJ, et al (2013) A comparison of visual- and stereo-video based fish community assessment methods in tropical and temperate marine waters of 
Western Australia: Comparison of fish community assessment methods. Limnol Oceanogr Methods 11:337-350. doi: 10.4319/lom.2013.11.337

Januchowski-Hartley FA, Graham NAJ, Cinner JE, Russ GR (2015) Local fishing influences coral reef fish behavior inside protected areas of the Indo-Pacific. Biol Conserv 182:8-12. doi: 10.1016/j.biocon.2014.11.024

Lindfield SJ, Harvey ES, McIlwain JL, Halford AR (2014) Silent fish surveys: bubble-free diving highlights inaccuracies associated with SCUBA-based surveys in heavily fished areas. Methods Ecol Evol 5:1061-1069. doi: 10.1111/2041-210X.12262

MacNeil MA, Graham NAJ, Cinner JE, et al (2015) Recovery potential of the world's coral reef fishes. Nature 520:341-344. doi: 10.1038/nature14358

Mallet D, Pelletier D (2014) Underwater video techniques for observing coastal marine biodiversity: a review of sixty years of publications (1952-2012). Fish Res 154:4462.

McClanahan TR, Graham NA, Wilson SK, et al (2009) Effects of fisheries closure size, age, and history of compliance on coral reef fish communities in the western Indian Ocean. Mar Ecol Prog Ser 396:99-109.

McClanahan TR, Graham NAJ, MacNeil MA, et al (2011) Critical thresholds and tangible targets for ecosystem-based management of coral reef fisheries. Proc Natl Acad Sci 108:17230-17233. doi: 10.1073/pnas.1106861108

Munday PL, Jones GP (1998) The ecological implications of small body size among coralreef fishes. Oceanogr Mar Biol Annu Rev 36:373-411.

Nash KL, Graham NAJ (2016) Ecological indicators for coral reef fisheries management. Fish Fish 17:1029-1054. doi: 10.1111/faf.12157

Pelletier D, Leleu K, Mou-Tham G, et al (2011) Comparison of visual census and high definition video transects for monitoring coral reef fish assemblages. Fish Res 107:84-93. doi: 10.1016/j.fishres.2010.10.011

Polunin NVC, Roberts CM (1993) Greater biomass and value of target coral-reef fishes in two small Caribbean marine reserves. Mar Ecol-Prog Ser 100:167-167.

Russ GR, Cheal AJ, Dolman AM, et al (2008) Rapid increase in fish numbers follows creation of world's largest marine reserve network. Curr Biol 18:R514-R515.

Ryan K., Hall N., Lai E., et al (2015) State-wide survey of recreational boat-based fishing in Western Australia 2013/14. Department of Fisheries, Western Australia, North Beach, WA

Sadovy de Mitcheson Y, Craig MT, Bertoncini AA, et al (2013) Fishing groupers towards extinction: a global assessment of threats and extinction risks in a billion dollar fishery. Fish Fish 14:119-136.

Sale PF, Sharp BJ (1983) Correction for bias in visual transect censuses of coral reef fishes. Coral Reefs 2:37-42. 
Sluka RD (2000) Grouper and Napoleon Wrasse ecology in Laamu Atoll, Republic of Maldives: Part 1. Habitat, behavior, and movement patterns. Atoll Res Bull 491:1-26. doi: 10.5479/si.00775630.491.1

Smallwood CB, Beckley LE (2012) Spatial distribution and zoning compliance of recreational fishing in Ningaloo Marine Park, north-western Australia. Fish Res 125126:40-50. doi: 10.1016/j.fishres.2012.01.019

Tessier E, Chabanet P, Pothin K, et al (2005) Visual censuses of tropical fish aggregations on artificial reefs: slate versus video recording techniques. J Exp Mar Biol Ecol 315:1730. doi: 10.1016/j.jembe.2004.08.027

Tolimieri N (2015) Density dependence and independence and the population dynamics of coral reef fishes. In: Mora C (ed) Ecology of Fishes on Coral Reefs. Cambridge University Press, Cambridge,

Trebilco R, Baum JK, Salomon AK, Dulvy NK (2013) Ecosystem ecology: size-based constraints on the pyramids of life. Trends Ecol Evol 28:423-431. doi: 10.1016/j.tree.2013.03.008

Turner JA, Polunin NVC, Field SN, Wilson SK (2015) Measuring coral size-frequency distribution using stereo video technology, a comparison with in situ measurements. Environ Monit Assess. doi: 10.1007/s10661-015-4431-8

Watson DL, Harvey ES, Fitzpatrick BM, et al (2010) Assessing reef fish assemblage structure: how do different stereo-video techniques compare? Mar Biol 157:12371250. doi: 10.1007/s00227-010-1404-x

Wilson SK, Babcock RC, Fisher R, et al (2012) Relative and combined effects of habitat and fishing on reef fish communities across a limited fishing gradient at Ningaloo. Mar Environ Res 81:1-11. doi: 10.1016/j.marenvres.2012.08.002

Wilson SK, Dolman AM, Cheal AJ, et al (2009) Maintenance of fish diversity on disturbed coral reefs. Coral Reefs 28:3-14. doi: 10.1007/s00338-008-0431-2 